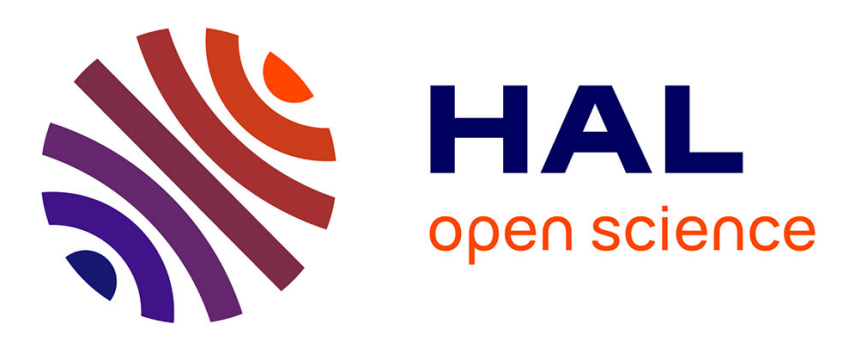

\title{
Ultrasonic effect on the photocatalytic degradation of Rhodamine 6G (Rh6G) dye by cotton fabrics loaded with TiO2
}

\author{
Luis Filipe V Ferreira, Zouhair Ait-Touchente, Ahmed M Khalil, Serap \\ Simsek, Sami Boufi, Luis Filipe V. Ferreira, Manuel Rei Vilar, Rachid \\ Touzani, Mohamed M Chehimi
}

\section{To cite this version:}

Luis Filipe V Ferreira, Zouhair Ait-Touchente, Ahmed M Khalil, Serap Simsek, Sami Boufi, et al.. Ultrasonic effect on the photocatalytic degradation of Rhodamine 6G (Rh6G) dye by cotton fabrics loaded with TiO2. Cellulose, 2020, 27 (2), pp.1085-1097. 10.1007/s10570-019-02817-y . hal03095935

\section{HAL Id: hal-03095935 https://hal.science/hal-03095935}

Submitted on 4 Jan 2021

HAL is a multi-disciplinary open access archive for the deposit and dissemination of scientific research documents, whether they are published or not. The documents may come from teaching and research institutions in France or abroad, or from public or private research centers.
L'archive ouverte pluridisciplinaire HAL, est destinée au dépôt et à la diffusion de documents scientifiques de niveau recherche, publiés ou non, émanant des établissements d'enseignement et de recherche français ou étrangers, des laboratoires publics ou privés. 

The Authors declare no conflict of interest.

\section{Ultrasonic effect on the photocatalytic degradation of Rhodamine 6G} (Rh6G) dye by cotton fabrics loaded with $\mathrm{TiO}_{2}$

\footnotetext{
Zouhair Ait-Touchente ${ }^{1}$, Ahmed M. Khalii ${ }^{2}$, Serap Simsek ${ }^{3}$, Sami Boufi ${ }^{4}$, Luis Filipe V. Ferreira ${ }^{5}$, Manuel Rei Vilar ${ }^{3}$, Rachid Touzani ${ }^{1}$, Mohamed M. Chehimi ${ }^{3,6, *}$

${ }^{1}$ LCAE-FSO, Université Mohammed Premier, Oujda 60000, Morocco

${ }^{2}$ Photochemistry Department, National Research Centre, Dokki 12622, Giza, Egypt

${ }^{3}$ ITODYS, UMR7086 CNRS, Université Paris Diderot, Sorbonne Paris Cité, Paris, France

${ }^{4}$ University of Sfax, Faculty of Science, LMSE, BP 1171-3000 Sfax, Tunisia

${ }^{5}$ Centro de Química-Física Molecular, IN and iBB, Instituto Superior Técnico, Universidade de Lisboa, Av. Rovisco Pais, 1049-001 Lisbon, Portugal

${ }^{6}$ Université Paris Est, ICMPE, UMR7182 CNRS, UPEC, F-94320 Thiais, France

*Corresponding authors: M. M. Chehimi, Université Paris Est, ICMPE, F-94320 Thiais, France (chehimi@icmpe.cnrs.fr)

E-mail addresses: $\quad$ zouhair.aittouchente@gmail.com (Z. Ait-Touchente), akhali175@yahoo.com (A. M. Khalil), tuncayserapsimsek@gmail.com (S. Simsek), sami.boufi@fss.rnu.tn (S. Boufi), luisfilipevf@tecnico.ulisboa.pt (L.F. Vieira Ferreira), manuel.rei-vilar@univ-paris-diderot.fr (M. Rei Vilar), chehimi@icmpe.cnrs.fr (M.M. Chehimi), r.touzani@ump.ac.ma (R.Touzani)
} 


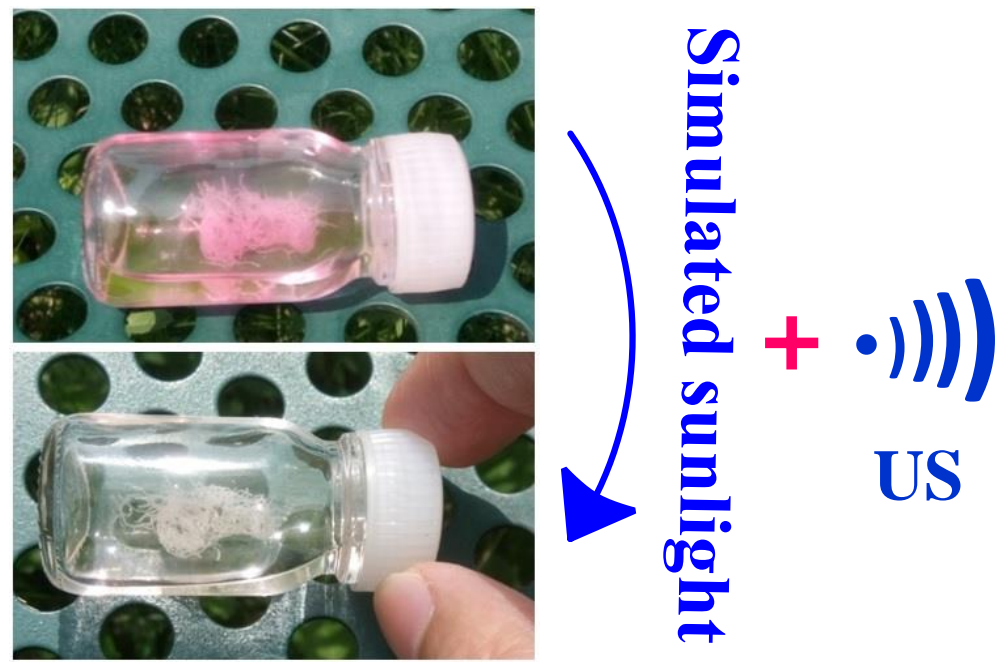

ABSTRACT

The effect of sonication on the photodegradation of Rhodamine $6 \mathrm{G}$ ( Rh6G, a fluorone dye) using woven cotton fabrics decorated with $\mathrm{TiO}_{2}$ nanoparticles (NPs) has been investigated. $\mathrm{TiO}_{2}$ NPs were synthesized in situ by sol-gel method in the presence of cotton textile and then hydrothermally treated. $\mathrm{TiO}_{2}$-loaded fabrics were treated ultrasonically to test adhesion to- and properties of the NPs on the fabrics. We demonstrate good adhesion and a good stability of the NPs of $\mathrm{TiO}_{2}$. Moreover, sonication substantially improved the distribution on the surfaces and hence enhanced the fabrics catalytic activity. Either under UV or simulated sunlight, ultrasonicated fabrics were found to have a high photocatalytic activity towards Rh6G, used as a model dye. SEM, XPS, UV-Vis and FTIR spectroscopy, as well as ground state diffuse reflectance (GSDR) and laser induced luminescence (LIL) were used to characterize fabrics/ $\mathrm{TiO}_{2}$ samples in terms of topography, surface composition, influence of hydrothermal treatment on photocatalytic activity, stability of $\mathrm{TiO}_{2}$ NPs, electro-optical properties of the modified fabrics, as well as the effect of ultrasonication on the photodegradation of Rh6G. This work paves the way to a larger scale improvement of the photocatalytic performances of $\mathrm{TiO}_{2}$-loaded cotton fabrics by post-sonication.

44 Keywords: cotton fabrics, $\mathrm{TiO}_{2}$ nanoparticles, adhesion, sonication, Rhodamine 6G, 45 photodegradation of dyes. 


\section{Introduction}

Currently, there is a growing demand for imparting textiles a technical property in addition to their intrinsic function of clothing. Indeed, functionalized textiles (Horrocks and Anand 2000; Blaser et al. 2008), are used for different applications such as comfort (odour elimination) (Yuranova et al. 2006; Chen et al. 2010), biomedical (prostheses, implants, bandages ...) (Li et al. 2015), civil engineering (composites, geotextile...) (Fangueiro 2011) and protection of individuals (protective clothing (Scott 2005), clothes for military (Wilusz 2008) or firemen (Hristian et al. 2014). Protection can also be provided for public ready-towear clothes using textiles with protective $\mathrm{TiO}_{2}$ nanoparticles. These nanomaterials protect the skin from the UV-B $(290-320 \mathrm{~nm})$ and UV-A $(320-400 \mathrm{~nm})$ regions of the solar spectrum (Popov et al. 2005), which consists of three ranges: UV-A, UV-B and UV-C (McKinlay 1987; Diffey 1991) (100 to $290 \mathrm{~nm}$ ) being almost completely absorbed by the ozone layer in the upper part of the Earth atmosphere.

To these above-mentioned remarkable features, one can also design textiles that possess photocatalytic properties imparted by immobilized $\mathrm{TiO}_{2}$ nanoparticles (Bozzi et al. 2005; Meilert et al. 2005; Xue et al. 2008; Abidi et al. 2009; Abid et al. 2016) for the elimination of dyes, fats, bacteria and viruses (Bozzi et al. 2005). It is well-known that titanium dioxide in its crystalline anatase form is considered as the semiconductor oxide having the highest photocatalytic activity and the best quantum yield (reaction rate in moles per second) (Hadjiivanov and Klissurski 1996). The photocatalytic activity of $\mathrm{TiO}_{2}$ rests on its excitation with light the energy of which $h v \geq \operatorname{Eg}$ (band gap energy) to create an electron pair $\left(\mathrm{e}^{-}\right) / \mathrm{hole}$ $\left(\mathrm{h}^{+}\right)$by the transfer of an electron of the valence band to the conduction band. This electron can be ejected and will react with oxygen adsorbed on the surface of $\mathrm{TiO}_{2}$, while the hole $\mathrm{h}^{+}$ created can react with surface water, forming highly oxidizing hydroxyl radicals $\left(\mathrm{OH}^{\circ}\right)$ responsible for the degradation of pollutants (Min et al. 2007; Salvador 2007; Tariq et al. 2008; Ochiai and Fujishima 2012). In addition to these salient chemical reactivity features, $\mathrm{TiO}_{2}$ is industrially employed due to its chemical stability, non-toxicity and low cost.

Either dyes or pigments employed in the textile industry undergo numerous testing; probably the most important one is colour fastness (Mohammad 2015; Rehman et al. 2017). It is thus important to investigate the adhesion of $\mathrm{TiO}_{2} \mathrm{NPs}$ to cotton textile in order to understand the shelf life of the textile and its long-term use to catalyse the degradation of dyes. Dealing with technical textile loaded with $\mathrm{TiO}_{2}$ immobilized for photocatalytic purpose, 
we have envisioned testing the stability of the immobilized nanocatalysts in terms of their (i) adhesion, and (ii) photoactivity. In an academic laboratory scale, ultrasonication remains a simple procedure to test the shaking off of the nanoparticles away from the textile support. However, it was also necessary to investigate the reminiscent photoactivity of the textiles after the adhesion testing.

In the recent literature, laboratory scale adhesion testing experiments, or in technical wording, "colour fastness" were conducted by (i) light exposure (Hinsch and Robinson 2018), (ii) washing and flexibility (Monzavi et al. 2017), and (iii) rubbing (Zou et al. 2018). In this context, we wished to contribute to this topic by bridging the gap between adhesion phenomena and photocatalysis. In the course of the investigation of adhesion of $\mathrm{TiO}_{2}$ to the textiles by an ultrasonic test ("ultrasonic colour fastness"), we surprisingly discovered that the ultrasonic waves increased the photocatalytic activity of $\mathrm{TiO}_{2} \mathrm{NPs}$. This good example of serendipity has encouraged us to deepen the study of the ultrasonic effect on the photocatalytic properties of $\mathrm{TiO}_{2}$-immobilized textiles.

In this paper, we describe the use of a cotton fabric that has been coated with $\mathrm{TiO}_{2}$ nanoparticles for the photocatalyzed destruction of Rhodamine 6G (Rh6G) taken as model organic dye as well as the frequently investigated Methylene Blue. The rationale for choosing these model compounds for testing textile photocatalyst is the following: Rhodamine 6G is a product with well-known toxicity. Its LD50 lethal dose is $89.5 \mathrm{mg} / \mathrm{kg}$ for rats. Rh6G is specifically used as a tracer dye in water to determine volumes, flow rates and directions of flow and transport. Methylene Blue is most often used as a disinfectant and can be found in natural waters through medical discharges. The presence of these two compounds in the aquatic environment can be harmful for the environment (Budavari et al. 1989; Program 1989; Djaneye-Boundjou et al. 2001; George and Kishen 2007).

The $\mathrm{TiO}_{2}$ NPs were prepared in situ in the presence of cotton fabric and activated by a hydrothermal treatment. The resulting hybrid textile has shown good photocatalytic activity for the degradation of Remazol Brilliant Blue R (Abid et al. 2016). This method of preparation of such specific fabrics is reliable and easy to produce. Although, much progress has been made in the production of $\mathrm{TiO}_{2}$-modified smart textiles, the examination of the photocatalytic properties of the final product after adhesion test of $\mathrm{TiO}_{2}$ remains sparse despite the technological interest of this kind of investigation to the textile industry, hence the motivation for this in-depth study. 
Nanostructured cotton samples were characterized by several techniques (SEM, XPS,

$111 \mathrm{UV}-\mathrm{Vis}$ and FTIR spectroscopy, GSDR and LIL). The final fabric/TiO ${ }_{2}$ was used to degrade

112 Rhodamine 6G. The photodegradation of the dye molecules in fabric/ $\mathrm{TiO}_{2}$-containing

113 solutions exposed to a sun simulator was monitored by the colour change, observed by naked

114 eye and UV/Vis absorption spectroscopy.

\section{Experimental}

\section{Chemicals}

Chemical reagents were provided by Sigma Aldrich were of analytical grade and used without further purification: $\mathrm{Ti}(\mathrm{OBu})_{4}$, glacial acetic acid, Rhodamine 6G ( 95\%), tertbutanol $99.7 \%$. Cotton fabrics were common gauze bandages with more than $99 \%$ of cellulose (purchased from Mega, Médicale Gaze S.A.).

\section{Preparation of cotton fabrics/ $\mathrm{TiO}_{2}$}

The cotton fabrics/ $/ \mathrm{TiO}_{2}$ samples were prepared as previously reported (Abid et al. 2016). It is a non-hydrolytic sol-gel process followed by a mild hydrothermal treatment at a temperature below $140{ }^{\circ} \mathrm{C}$. We used samples prepared at different temperatures $(50,110,120$ and $\left.140{ }^{\circ} \mathrm{C}\right)$.

\section{Sonication of cotton fabrics}

The samples were placed in vials containing deionized water and subjected to 128 ultrasonication in a sonocleaner (Bandelin, Sonorex Digitec model; $860 \mathrm{~W}, 35 \mathrm{kHz}$ ) for 5, 15 129 or 30 min. After sonication, they were washed with water, and dried for further studies.

\section{Characterization}

Scanning electron microscopy images were recorded using a Field Emission Scanning

132 Electron Microscope (FE-SEM) ZEISS SUPRA40, previously described (Abid et al. 2016).

X-ray photoelectron spectroscopy (XPS) measurements were recorded using a K Alpha system (Thermo Fisher Scientific) fitted with Al X-ray source (hv=1486.6 eV; spot size $=400 \mu \mathrm{m})$ and an electron flood gun. Surface composition was determined using the manufacturer's sensitivity factors. 
FTIR spectra were acquired using a Bruker Tensor 27 IR spectrometer in the range of $400-4000 \mathrm{~cm}^{-1}$ spectral region. Samples were first washed 3 times with distilled water and dried before analysis.

Ground state diffuse reflectance (GSDR) absorption spectra were recorded using an OLIS 14 spectrophotometer with a diffuse reflectance attachment. Further details are given elsewhere (Vieira Ferreira and Ferreira Machado 2007; Errokh et al. 2016).

The set-up for the laser induced luminescence (LIL) was described in the literature (Errokh et al. 2016). Time-resolved emission spectra were performed in the nanosecond to second time range with a $\mathrm{N}_{2}$ laser (excitation wavelength=337 nm, PTI model 2000, ca. 600 ps FWHM, about $1 \mathrm{~mJ}$ per pulse). Emission spectra were obtained at $77 \mathrm{~K}$, due to the fact 148 that, at the room temperature, luminescence intensity is negligible for the anatase form of $\mathrm{TiO}_{2}$.

\section{Photocatalytic measurements}

The irradiation tests were carried out using UVACUBE400 photoreactor, producing a simulated sunlight; this device was used to test the photocatalytic activity of the cotton fabrics $/ \mathrm{TiO}_{2}$ samples. All measurements were performed with $30 \mathrm{mg}$ (per step) of fabric/ $/ \mathrm{TiO}_{2}$

154 equilibrium. The absorbance of the Rh6G solution was monitored using a Varian Cary 50 Bio

155 UV-visible spectrophotometer controlled by the CaryWinUV software.

\section{Results and discussion}

158 The sequential steps of the work are presented in Fig. 1. In the first step of the 159 preparation of cotton- $\mathrm{TiO}_{2}$, woven cotton samples were immersed in a solution of $\mathrm{Ti}(\mathrm{OBu})_{4}$ in 160 tert-butanol for 12 hours at room temperature. Then, after drying, the cotton fabrics were 161 subjected to mild hydrothermal treatment for 3 hours at indicated temperature to crystallize 162 the $\mathrm{TiO}_{2}$ layer generated on the surface of the cotton fibers (Abid et al. 2016). These samples 163 have been tested to determine optimal conditions for high performance photocatalytic activity.

164 Cotton- $\mathrm{TiO}_{2}$ samples were then sonicated at room temperature (Fig. 1(a)). $30 \mathrm{mg}$ of 165 each sample was placed in a beaker containing $10 \mathrm{ml}$ of distilled water and sonicated for 30 166 minutes. 
(a)

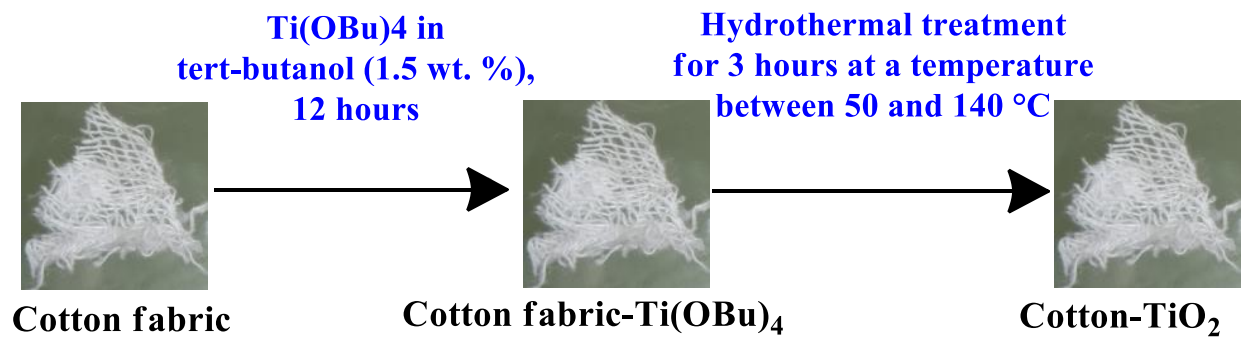

(b)
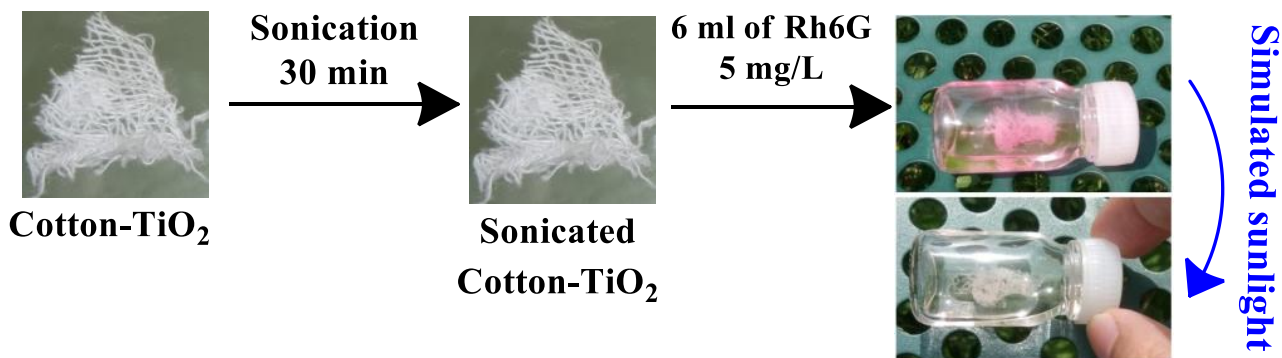

168 Fig. 1 Illustration of the different steps followed to : (a) prepare different cotton- $\mathrm{TiO}_{2} \mathrm{NPs}$ samples 169 and (b) sonication and photodegradation of Rh6G.

\section{Scanning electron microscopy (SEM)}

The SEM images of the different cotton samples are shown in Fig. 2. The morphology

172 of cotton cellulose fibres prior to hydrothermal treatment is shown in Fig. 2(a). In situ

173 synthesis of $\mathrm{TiO}_{2}$ nanoparticles the latter for a very thin layer that is topping the cotton fibres.

174 The mean size of the $\mathrm{TiO}_{2}$ NPs is less than $20 \mathrm{~nm}$ for the hydrothermal treatment at $120{ }^{\circ} \mathrm{C}$. 

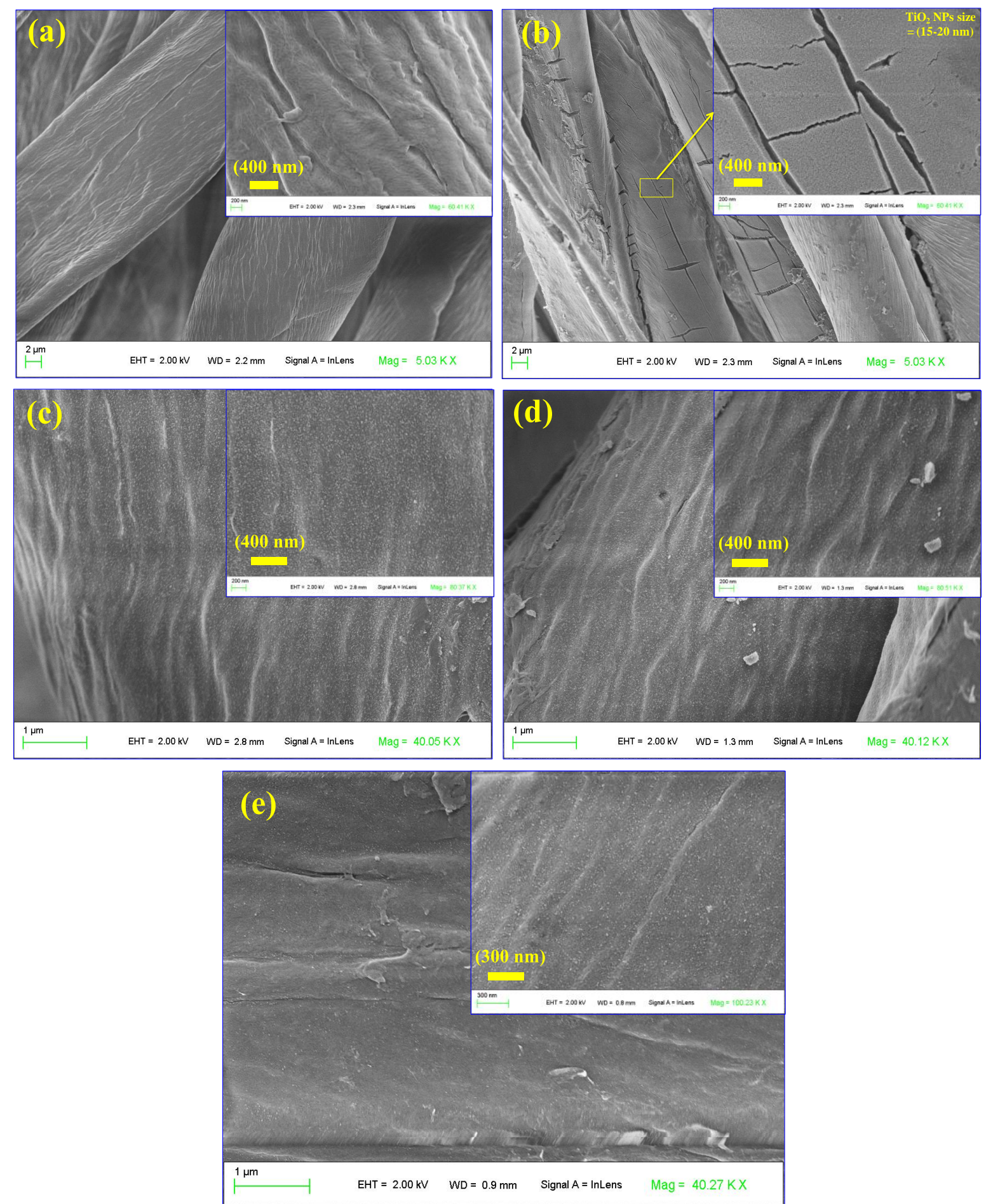

Fig. 2 SEM images: (a) top view of pristine cotton substrate; (b) cotton fabric/ $/ \mathrm{TiO}_{2}-120{ }^{\circ} \mathrm{C}$; (c) sonicated cotton fabric/TiO ${ }_{2}^{-}$ $120{ }^{\circ} \mathrm{C} / 5 \mathrm{~min}$; (d) sonicated cotton fabric/TiO ${ }_{2}-120^{\circ} \mathrm{C} / 30 \mathrm{~min}$ and (e) cotton fabric/ $\mathrm{TiO}_{2}-120{ }^{\circ} \mathrm{C}$ after 4 hours and $30 \mathrm{~min}$ exposure to simulated sunlight

Fabric/TiO ${ }_{2}$ samples were sonicated for 5, 15 and 30 minutes to test the adhesion

180 between the $\mathrm{TiO}_{2}$ NPs layer and the woven cotton surface. Fig. 2(c) shows $\mathrm{Fabric} / \mathrm{TiO}_{2}-$

$181120{ }^{\circ} \mathrm{C}$ after 5 minutes of sonication; one can note that the $\mathrm{TiO}_{2} \mathrm{NPs}$ layer withstands

182 sonication even after 30 minutes of sonication. Another important observation concerns the 
183

184

185

186

187

188

189

190

191

192

193

194

195

196

197

198

199

200

201

202

203

204

205

206

207

208

209

210

211

homogeneous spreading of $\mathrm{TiO}_{2} \mathrm{NPs}$ over the entire cotton fabrics (Figs. 2(c-d)) compared to the surface shown in Fig. 2(b). To study the robustness of the catalytic property of the $\mathrm{TiO}_{2^{-}}$ containing fabric relatively to the irradiation of the simulated sunlight, a UVACUBE400 reactor was used. Indeed, the exposure of fabric/ $\mathrm{TiO}_{2}$ for one hour in the sun simulator corresponds to about 9 days and 2 hours of exposure to the sun. The fabric/ $/ \mathrm{TiO}_{2}$ sample is introduced in a tube and stays under insolation for 4 hours and $30 \mathrm{~min}$ in the photoreactor, corresponding to 40 days and 9 hours of day light exposure. SEM image shown in Fig. 2(e) confirms that the simulated sunlight treated surface remains identical to the sonicated one (image (d)).

\section{X-ray photoelectron spectroscopy (XPS)}

Fig. 3 displays XPS spectra of untreated cotton (Fig. 3 (a, c, e, g)) and $\mathrm{TiO}_{2}$ loaded cotton fabric $-120^{\circ} \mathrm{C}(\mathrm{b}, \mathrm{d}, \mathrm{f}, \mathrm{h})$. Survey regions are displayed in Fig. 3 (a (untreated cotton) and $\mathrm{b}\left(\mathrm{Fabric} / \mathrm{TiO}_{2}-120^{\circ} \mathrm{C}\right)$ ); and the main peaks are $\mathrm{C} 1 \mathrm{~s}(285 \mathrm{eV})$, Ti2p $(459 \mathrm{eV})$ and $\mathrm{O} 1 \mathrm{~s}$ $(532 \mathrm{eV})$. The untreated cotton does not contain $\mathrm{TiO}_{2} \mathrm{NPs}$, which was confirmed by the shape of Ti2p line obtained in Fig. 3(g), whereas fabric/TiO ${ }_{2}-120{ }^{\circ} \mathrm{C}$ spectrum exhibits a peak at $459 \mathrm{eV}$ corresponding to Ti2p (Fig. 3(h)), which proves that the immobilization step of $\mathrm{TiO}_{2}$ NPs on cotton samples was successfully accomplished. The $\mathrm{C} 1 \mathrm{~s}$ region presented in Fig. 3(c, d) was fitted with four components centred at 285.0, 286.6, 288.3 and $289.5 \mathrm{eV}$, assigned to: $\mathrm{C}-\mathrm{C} / \mathrm{C}-\mathrm{H}$ bonds derived from the hydrocarbon contamination or treatment of cotton fabrics (sizing); C-O-C/C-OH, O-C-O bonds corresponding to the hemi-acetal group characteristic of cellulose; and finally, an oxidation peak which corresponds to an ester or an adsorbed carbonate. Since a cellulose unit has only one hemiacetal carbon atom, we will choose this atom as a marker element for cellulose in the following (Belgacem et al. 1995; Attia et al. 2013).

The O1s XPS region presented in Fig. 3 (e) reveals an asymmetric peak at $533.0 \mathrm{eV}$ attributed to $\mathrm{C}-\mathrm{O}$ bonds in cellulose and other organic compounds. While for fabric/ $\mathrm{TiO}_{2}$ $120^{\circ} \mathrm{C}$, there is an additional contribution centred at $530.5 \mathrm{eV}$, which is characteristic of metallic oxides and herein assigned to Ti-O bond (Atashbar et al. 1998). 


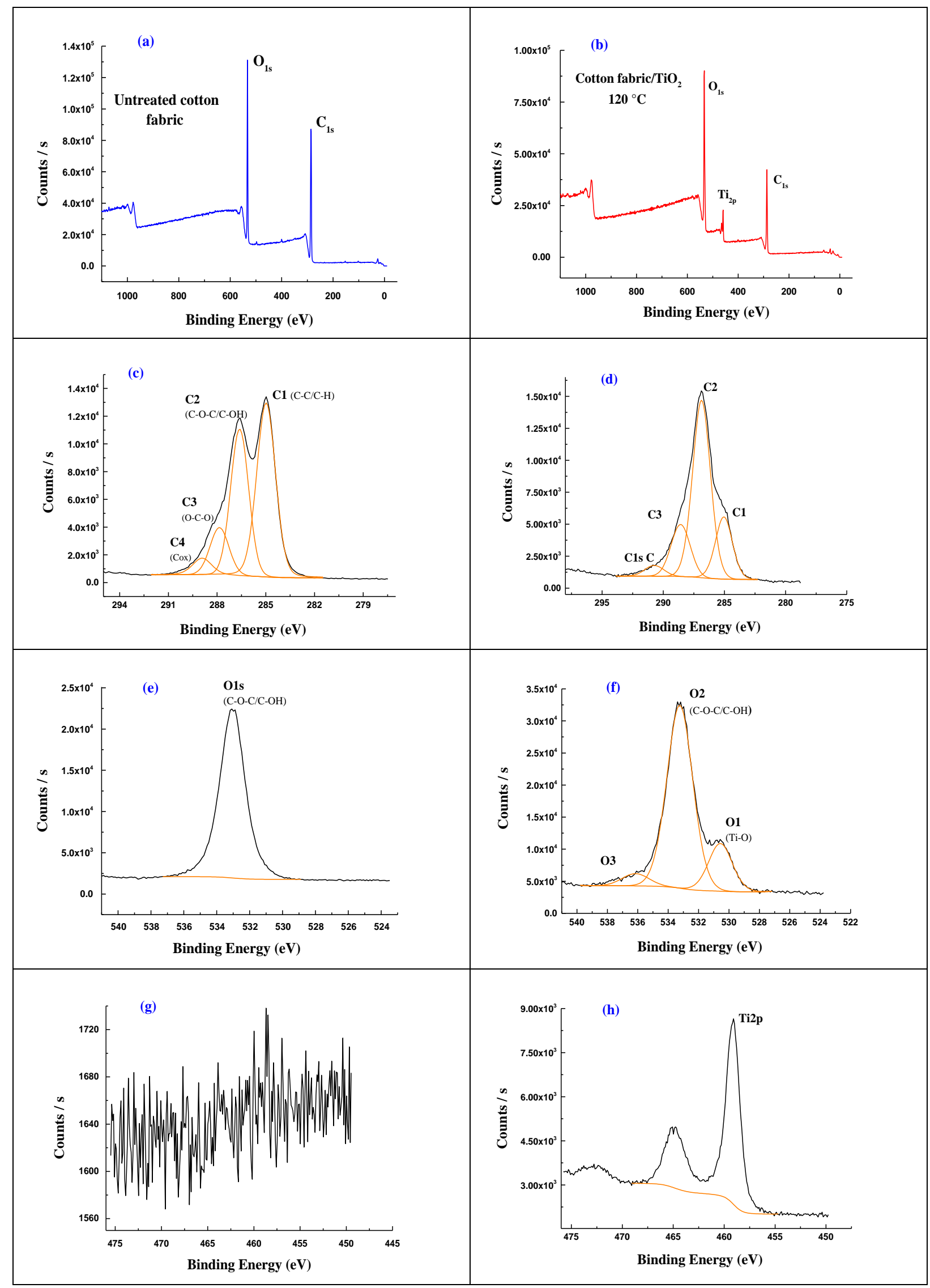

Fig. 3 XPS spectra of untreated cotton fabric (a, c, e, g) and cotton fabric/ $\mathrm{TiO}_{2}-120{ }^{\circ} \mathrm{C}(\mathrm{b}, \mathrm{d}, \mathrm{f}, \mathrm{h})$ 
XPS spectra were recorded for fabrics/ $\mathrm{TiO}_{2}-\left(50,110\right.$ and $\left.140{ }^{\circ} \mathrm{C}\right)$. Table 1 shows the 214 chemical composition of the untreated and $\mathrm{TiO}_{2}$ loaded cotton fabrics. The cotton fabric used 215 is contaminated even if it is a sterile sample. In fact, hydrocarbons contribute $33.2 \%$ to the 216 composition of untreated cotton (regardless of hydrogen). Once $\mathrm{TiO}_{2}$ has been deposited, this 217 contribution is substantially reduced. We note also that the atomic percentage of $\mathrm{TiO}_{2}$ is 218 higher for the refluxed cotton fabric sample at $120{ }^{\circ} \mathrm{C}$; this variation may be due to the 219 difference in reflux temperatures.

220 Table 1 Surface chemical composition of untreated and $\mathrm{TiO}_{2}$ loaded woven cotton fabrics

\begin{tabular}{|c|c|c|c|c|c|c|c|}
\hline Samples & $\begin{array}{c}\mathrm{C1} \\
(\mathrm{C}-\mathrm{C} / \mathrm{C}-\mathrm{H}) \\
\end{array}$ & $\begin{array}{c}\mathrm{C} 2 \\
(\mathrm{C}-\mathrm{O}-\mathrm{C} / \mathrm{C}-\mathrm{OH}) \\
\end{array}$ & $\begin{array}{c}\mathrm{C3} \\
(\mathrm{O}-\mathrm{C}-\mathrm{O})\end{array}$ & $\begin{array}{c}\mathrm{C4} \\
\left(\mathrm{CO}_{\mathrm{x}}\right) \\
\end{array}$ & $\begin{array}{c}\mathrm{O1} \\
\left(\mathrm{TiO}_{2}\right) \\
\end{array}$ & $\begin{array}{c}\mathrm{O2} \\
\text { (org) }\end{array}$ & $\mathbf{T i}$ \\
\hline $\begin{array}{c}\text { Untreated cotton } \\
\text { fabric }\end{array}$ & 33.20 & 25.90 & 8.86 & 3.51 & - & 28.60 & - \\
\hline Fabric/TiO $_{2}-50{ }^{\circ} \mathrm{C}$ & 11.23 & 29.75 & 12.74 & 2.52 & 3.72 & 38.11 & 1.92 \\
\hline Fabric/TiO $_{2}-110{ }^{\circ} \mathrm{C}$ & 14.64 & 30.16 & 10.06 & 2.13 & 7.56 & 33.10 & 2.45 \\
\hline${\text { Fabric} / \mathrm{TiO}_{2}-120}^{\circ} \mathrm{C}$ & 11.01 & 32.89 & 10.20 & 2.10 & 7.42 & 12.30 & 3.14 \\
\hline 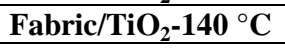 & 18.75 & 25.34 & 9.54 & 3.11 & 6.24 & 34.10 & 3.01 \\
\hline
\end{tabular}

In order to study the effect of the adhesion test (sonication) on the fabric/ $\mathrm{TiO}_{2}$ as well as

222 the effect of the exposure to simulated sunlight on the stability of the photocatalytic activity of $223 \mathrm{TiO}_{2} \mathrm{NPs}, 4$ samples of $30 \mathrm{mg}$ of cotton fabric/TiO ${ }_{2}-120{ }^{\circ} \mathrm{C}$ were taken for post-treatment 224 under ultrasonic waves for 5, 15 and $30 \mathrm{~min}$, respectively; and the 4th sample was placed in 225 the photoreactor for an insolation of $4 \mathrm{~h} 30$. These samples were then analysed in XPS, and the 226 ratio Ti/C3 (Fig. 4) was compared, Ti being the marker element of titanium oxide and $\mathrm{C} 3$ that 227 of cellulose. One can remark that the atomic percentage of Ti increases from a non-post228 treated fabric/ $\mathrm{TiO}_{2}-120{ }^{\circ} \mathrm{C}$ to a sonicated sample and the sonication time. This may be due to 229 the fact that sonication leaves the distribution of $\mathrm{TiO}_{2} \mathrm{NPs}$ more homogeneous on the surface 230 of the cotton fibres, improving the screening of the fabric. The ratio Ti/C3 for the insolated 231 sample for 4 hours $30 \mathrm{~min}$ still reveals a high percentage of $\mathrm{Ti}$, confirming that titanium oxide 232 remains on the fabric surface despite the long treatment in the photoreactor. 


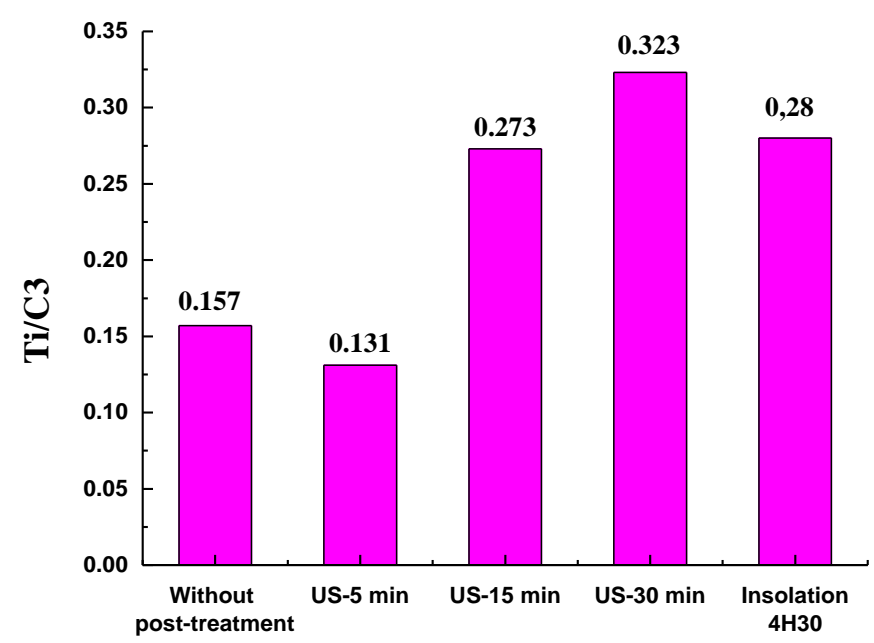

Fig. 4 Atomic ratios (Ti/C3) of samples untreated or treated (sonication and insolation) undergone by a fabric/TiO ${ }_{2}-120{ }^{\circ} \mathrm{C}$ sample

\section{Effect of fabric/ $\mathrm{TiO}_{2}$ treatment on the catalysed photodegradation of}

\section{Rhodamine 6G}

Stability of the dye and degradation time

Prior to any photocatalytic test, a $5 \mathrm{mg} / \mathrm{L}$ aqueous solution of the model dye Rhodamine 6G (Rh6G) was exposed to simulated sunlight in the absence of the fabric. Similarly, spectra of $\mathrm{Rh} 6 \mathrm{G}$ solutions exposed to the photoreactor in the presence of fabric/ $\mathrm{TiO}_{2}-120{ }^{\circ} \mathrm{C}$ were recorded to check the stability of the dye before and after contact with the photocatalytic

244 Rh6G dye. It should be noted that the aqueous solution of Rh6G gives a peak at $525 \mathrm{~nm}$ and 245 after exposure to the simulated sunlight, the absorbance remains the same, that is to say that 246 the Rh6G was not degraded under irradiation at photoreactor for 120 minutes. This indicates 247 that this dye is stable and can be used for testing the photocatalytic activity of the textile catalytic samples as it does not give any false positive result. 


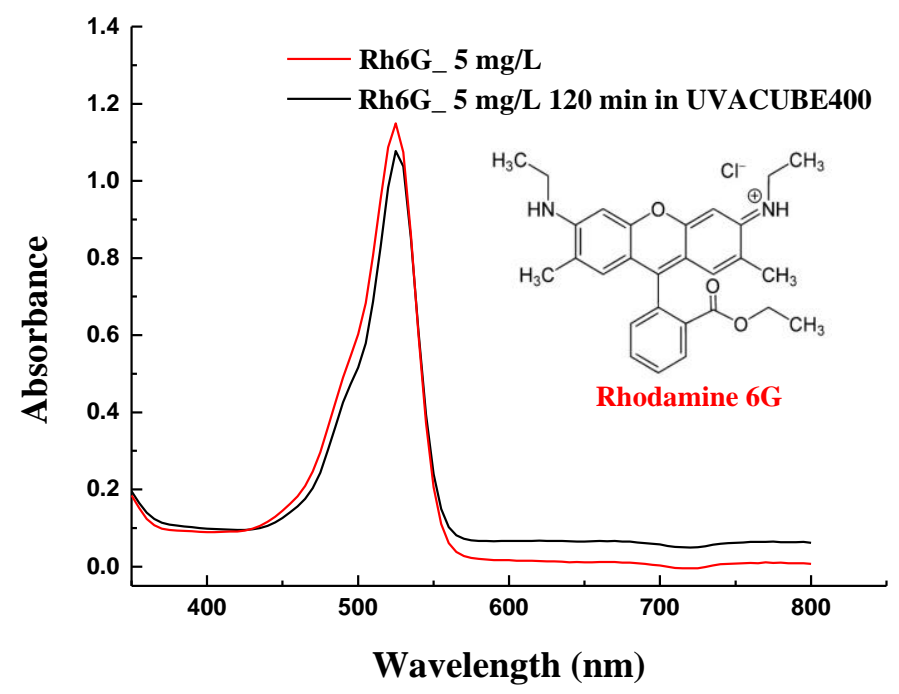

Fig. 5 UV-Vis absorption spectra of Rh6G before and after irradiation in the UVACUBE400 photoreactor

To optimize the exposure time of the dye/textile mixture to light, several tests at 252 different time intervals (20, 40, 60 and $120 \mathrm{~min}$ ) were performed, considering the start time $253 \mathrm{t}_{0}=45$ min prior in the obscurity. The different UV-vis spectra compared in Fig.6, which show 254 a progressive decrease in the maximum intensity of the initial Rh6G solution in the presence 255 of fabric/ $\mathrm{TiO}_{2}-120{ }^{\circ} \mathrm{C}$ from the beginning up to 2 hours of the insolation exposure. After 256120 min exposure of the Rh6G dye to light, the aqueous solution becomes colourless, which is 257 here conferred to the activity of the photocatalytic textile, proving the photocatalytic activity 258 of $\mathrm{TiO}_{2}$ nanoparticles immobilized on the cotton fibres. However, the photocatalytic activity 259 decreases after several operations. This may be associated to the presence of aggregating by260 products on the surface of the photocatalyst (Hamden et al. 2014). On the one hand, Rh6G is 261 stable after long exposure to simulated sunlight, and on the other hand the textile catalyst is 262 active and induces bleaching of the dye. 


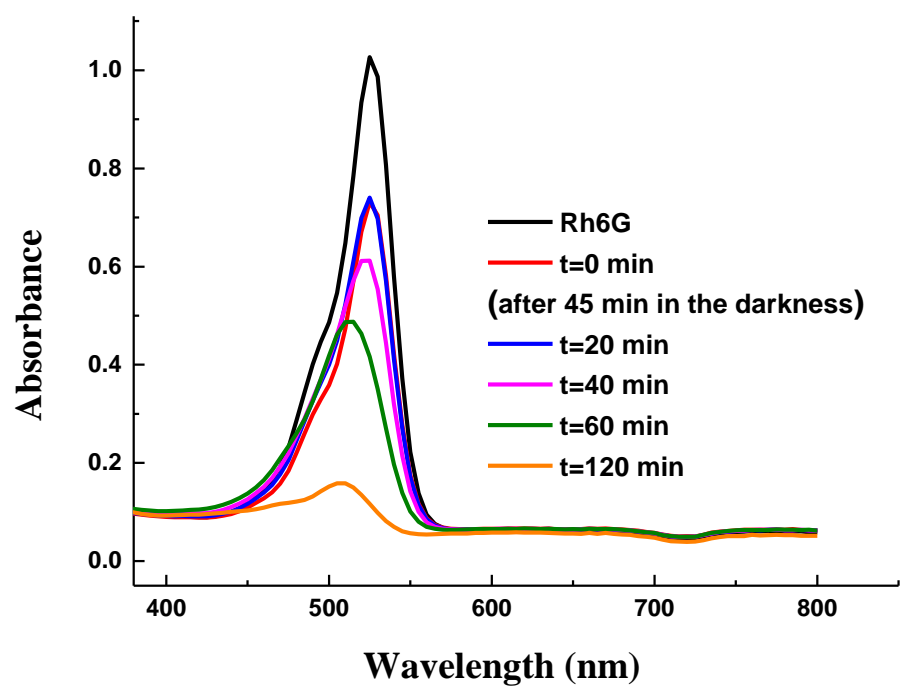

264 Fig. $6 \mathrm{UV}-\mathrm{Vis}$ absorption spectra of $\mathrm{Rh} 6 \mathrm{G}$ with and without fabric/TiO2-120 ${ }^{\circ} \mathrm{C}$ at different time intervals under UV 265 irradiation

Dual effects of hydrothermal and post-sonication treatments on the catalytic fabrics

The treated fabric/ $/ \mathrm{TiO}_{2}$ hybrid nanocomposites were refluxed to 50, 110, 120 and $140{ }^{\circ} \mathrm{C}$ then introduced to $\mathrm{Rh} 6 \mathrm{G}$ aqueous solution before exposure to simulated sunlight. After sunlight irradiation for 120 minutes, all vials turned colourless which denotes the effective photocatalytic activity of the immobilized $\mathrm{TiO}_{2}$ NPs. The sharp decrease in absorbance after exposure of the dye/textile mixtures to light in Fig. 7(a) emphasizes the successful photocatalytic degradation of $\mathrm{Rh} 6 \mathrm{G}$ in the presence of the refluxed fabrics after 273 being UV irradiated for 120 minutes.

Furthermore, the hydrothermal treatment carried out at different temperatures undergone by the fabric/ $\mathrm{TiO}_{2}$ influences the catalytic power of $\mathrm{TiO}_{2} \mathrm{NPs}$. It is noted that the optimum temperature for photodegradation of $\mathrm{Rh} 6 \mathrm{G}$ is $120^{\circ} \mathrm{C}$ (Fig. 7(a)). At higher temperature; namely $140{ }^{\circ} \mathrm{C}$, we have a higher absorbance value than that obtained for the fabric prepared at $120{ }^{\circ} \mathrm{C}$ indicating a decrease in the photocatalytic activity at higher temperatures than $120{ }^{\circ} \mathrm{C}$ as previously reported (Abid et al. 2016).

An approach by means of ultrasonication (US) has been endeavoured with fabric/ $/ \mathrm{TiO}_{2}$ to test the adhesion of $\mathrm{TiO}_{2}$ to the cotton fabric. Three vials; each containing (30 $\mathrm{mg}$ of treated $282 \mathrm{fabric} / \mathrm{TiO}_{2}$ ) were ultrasonicated for 5, 15 and $30 \mathrm{~min}$. Then, the samples were washed 3 times 283 with distilled water. This was followed by placing $6 \mathrm{ml}$ of the prepared Rh6G solution in each 
284 vial containing the ultrasonicated treated fabrics and subjecting them to simulated sunlight 285 exposure for 120 minutes. The effect of post-sonication is shown in Fig.7(a) (red bars). As 286 one can observe, there is a significant decrease in absorbance compared to non-ultrasound 287 samples. This means that despite partial removal of the catalytic nanoparticles, the fabrics 288 retain photocatalytic activity. Surprisingly, the decrease in the spectral peak intensity of the 289 dye is systematically lower for post-sonicated hydrothermally treated fabrics, up to $120{ }^{\circ} \mathrm{C}$. 290 This difference is significant and is not contained within the error bars, therefore testifying a 291 true synergetic effect of ultrasonication on the fabric. There is an exception for the $\mathrm{TiO}_{2}-$ 292 modified fabric that has been treated hydrothermally at $140{ }^{\circ} \mathrm{C}$ : we noted slight increase of 293 absorbance, mostly due to slight adhesion loss of $\mathrm{TiO}_{2}$ nanoparticles. Indeed, XPS analysis of 294 cotton- $\mathrm{TiO}_{2}$ samples reported in Table 1 shows that annealed sample at $140{ }^{\circ} \mathrm{C}$ has a $\mathrm{Ti}$ at.\% 295 of $3.01 \%$, slightly lower compared to $3.14 \%$ for $120{ }^{\circ} \mathrm{C}$ annealing temperature. Sonication 296 does not improve the photocatalytic character of the fabric annealed at $140{ }^{\circ} \mathrm{C}$; for this reason 297 we further examined the performances of the fabric annealed at $120^{\circ} \mathrm{C}$ (see Fig. 7b). 

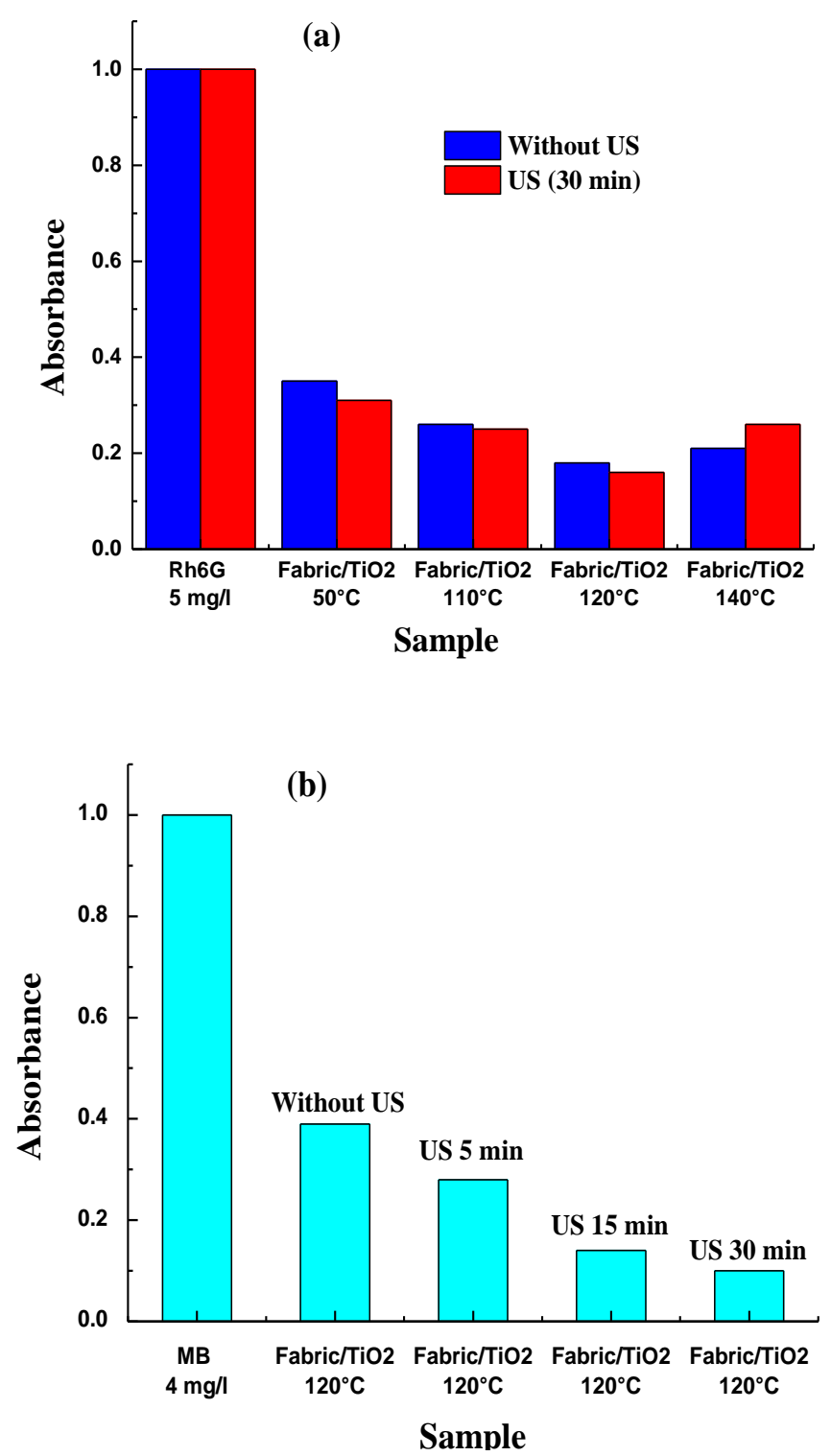

302 Fig. 7 (a) UV-Vis absorption spectra of Rh6G after photocatalytic degradation in the presence of non-sonicated and sonicated 303 fabric/ $/ \mathrm{TiO}_{2}$ refluxed at $\left(50,110,120\right.$ and $\left.140{ }^{\circ} \mathrm{C}\right)$ subjected to UV irradiation. (b) Photodegradation spectrum of methylene 304 blue with fabric/ $\mathrm{TiO}_{2}-120^{\circ} \mathrm{C}$ with and without sonication

To confirm that sonication increases the photocatalytic effect of $\mathrm{TiO}_{2} \mathrm{NPs}$, we repeated 306 a similar experiment with a fabric that has been hydrothermally treated at $120{ }^{\circ} \mathrm{C}$. Three 307 samples of this fabric were post-sonicated for 5, 15 and $30 \mathrm{~min}$ and then used to catalyse the 308 photodegradation of Methylene Blue, MB (Fig.7(b)). It is clear that the fabric continues to act 309 as a true photocatalyst after sonication since the maximum absorbance of the MB decreases 310 by $60 \%$ compared to the pure MB solution $(4 \mathrm{mg} / \mathrm{L})$ after a short sonication period 
311 (5 minutes). On the other hand, after a sonication of 30 minutes, one reaches to attain $90 \%$ of 312 degradation of MB.

313 The results displayed in Fig. 7 demonstrate the important improvement of the 314 photocatalytic performances of $\mathrm{TiO}_{2}$ loaded cotton fabrics. This unexpected result, accounts 315 for the morphology displayed in the SEM images, which show that after sonication the 316 surface of the cotton becomes more homogeneous. Possibly, with an even distribution of the 317 cotton fabric, a larger specific surface was achieved by the $\mathrm{TiO}_{2}$ NPs that remained on the 318 textile.

The adhesion between the cotton fabric and $\mathrm{TiO}_{2}$ after sonication has been studied by FT-IR spectroscopy in transmission mode. Hence, the treated fabrics were washed 3 times

321 with distilled water and dried before analysed by FTIRS. Fig. 8 illustrates the infrared spectra 322 of treated fabric/ $/ \mathrm{TiO}_{2}$, showing no changes in the wave numbers of the characteristic peaks of 323 the three treated samples after 5, 15 and 30 minutes of sonication. Cellulosic chains are 324 characterized by different bands, a broad one corresponding to the $\mathrm{O}-\mathrm{H}$ stretching located at $3253320 \mathrm{~cm}^{-1}$, the $\mathrm{C}-\mathrm{H}$ stretching at $2886 \mathrm{~cm}^{-1}$ with the corresponding $\mathrm{C}-\mathrm{H}$ bending at $1430 \mathrm{~cm}^{-1}$, $326-\mathrm{O}-\mathrm{H}$ bending at 1630 and at $1418 \mathrm{~cm}^{-1}$ stretching vibrations. In addition, the peak at $3271031 \mathrm{~cm}^{-1}$ refers to symmetric and asymmetric stretching C-O-C bonds. The peak that appears 328 at $690 \mathrm{~cm}^{-1}$ is assigned to Ti-O-O bond and accounts for the presence of $\mathrm{TiO}_{2}$ after sonication. 329 These results show that despite this strong sonication test, the characteristic peak of $\mathrm{TiO}_{2} \mathrm{NPs}$ 330 is always present. 


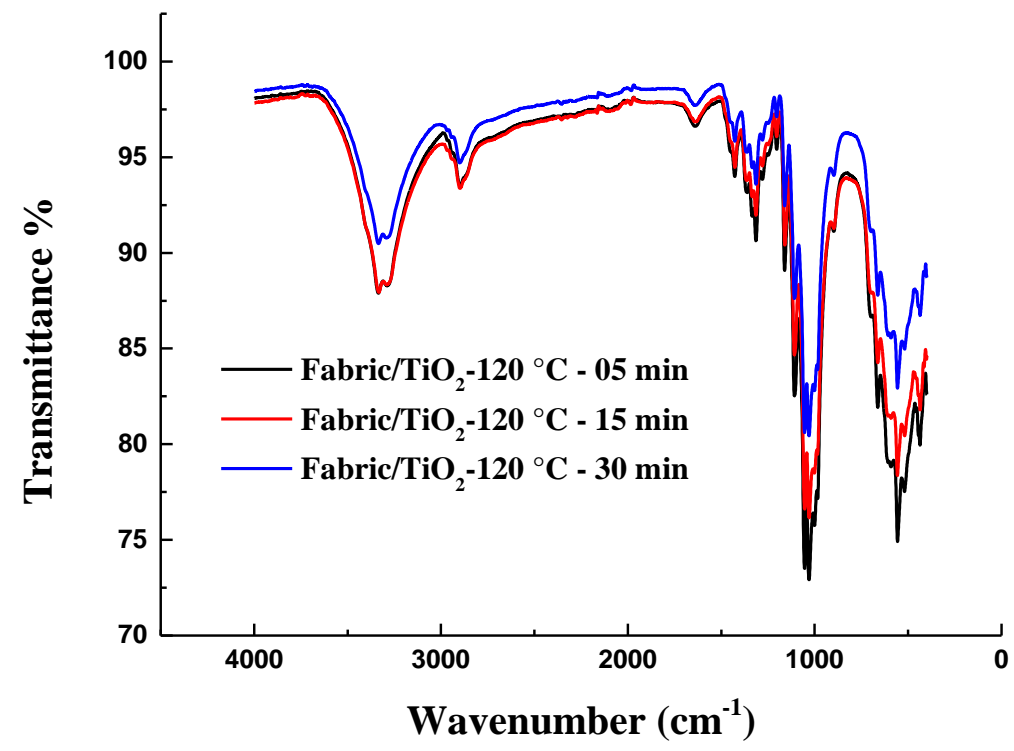

Fig. 8 FTIR spectra of treated $\mathrm{Fabric} / \mathrm{TiO}_{2}-120{ }^{\circ} \mathrm{C}$ ultrasonicated during 5,15 and 30 minutes

\section{Ground-state diffuse reflectance}

The ground-state diffuse reflectance spectra of fabric/ $\mathrm{TiO}_{2}$ before and after ultrasonic vibration are shown in Fig. 9. The UV absorption band at about $310 \mathrm{~nm}$ corresponding to $\mathrm{TiO}_{2}$, already studied and reported in a previous work (Abid et al. 2016), proves the existence of $\mathrm{TiO}_{2}$ NPs on cotton fibres.

The presence of the same peak at about $312 \mathrm{~nm}$ after sonication shows that this test does not detach the $\mathrm{TiO}_{2}$ NPs from the cotton substrate, i.e. the bond is strong between the $\mathrm{TiO}_{2}$ NPs and cotton fibres.

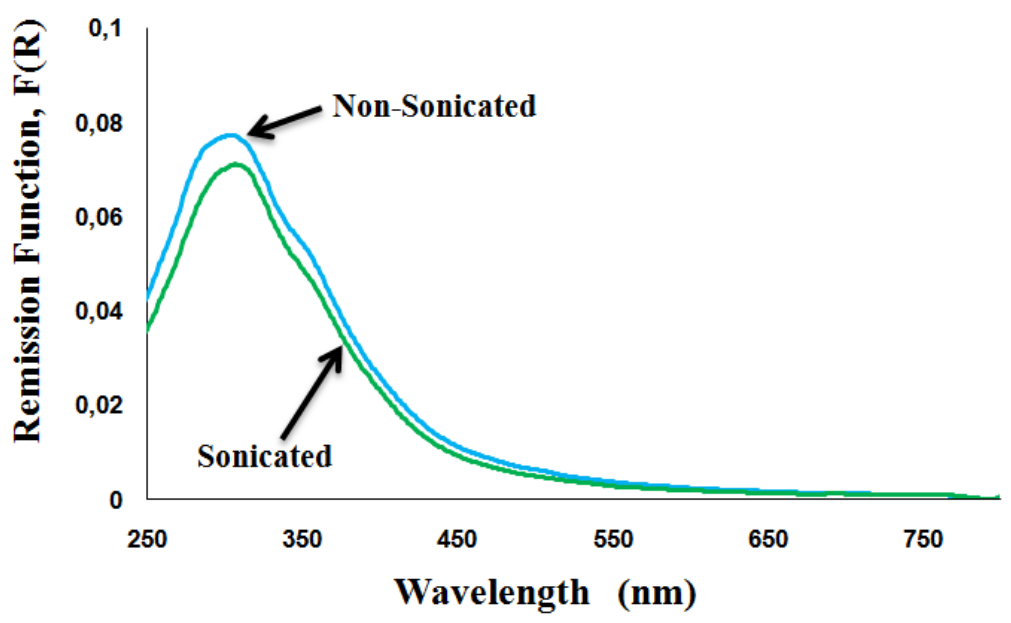


However, a small amount of $\mathrm{TiO}_{2}$ is detached from the substrate, as the decrease of the

344 remission function value for the sonicated sample clearly shows.

\section{Laser induced luminescence}

The laser induced luminescence spectra $\left(\lambda_{\text {exc }}=337 \mathrm{~nm}, \sim 1.3 \mathrm{~mJ}\right.$ per excitation pulse $)$, at

$34777 \mathrm{~K}$, for the fabric/ $\mathrm{TiO}_{2}$ samples are illustrated in Fig. 10(a). The initial curve was obtained 348 after laser pulse, and the following curves were obtained with the step of $1000 \mathrm{~ns}$. The gate 349 width was $10 \mathrm{~ms}$. The laser induced emission spectra of non-sonicated fabric/TiO ${ }_{2}$ are 350 displayed with maxima at $533 \mathrm{~nm}$. The maximum emission of non-sonicated fabric/TiO ${ }_{2}$, was 351 obtained with a maximum of about $533 \mathrm{~nm}$ (Fig. 10(a)) and a luminescence intensity of about 352150000 (a.u.). These spectra reflect a simultaneous emission of cotton and $\mathrm{TiO}_{2}$ with a greater 353 contribution of the latter. After ultrasonic treatment with fabric/TiO ${ }_{2}-120{ }^{\circ} \mathrm{C}$ (Fig. 10 (b)), the 354 luminescence intensity increases to about 230000 (a.u.). This large difference between the two 355 spectra is certainly due to the effect of sonication on the distribution and the organization of $356 \mathrm{TiO}_{2}$ NPs immobilized on the fabric. Only the better attached $\mathrm{TiO}_{2} \mathrm{NPs}$ remain on the surface 357 and possibly the number of surface defects decreases with sonication, meaning that the 358 number of traps for the excited $\mathrm{TiO}_{2}$ to be deactivated by a non-radiative pathway also 359 decreases. Therefore, the luminescence intensity of $\mathrm{TiO}_{2}$ increases for the sonicated sample 360 and also the half-life is about $1.5 \mu \mathrm{s}$, while the non-sonicated sample exhibits a shorter half361 life, at least in the initial times of its decay. These data also support the interpretation that the 362 remaining $\mathrm{TiO}_{2}$ NPs (after sonication) contain less defects (traps), therefore larger intensities 363 for irs luminescence and larger lifetimes for the $\mathrm{TiO}_{2} \mathrm{NPs}$ are observed.
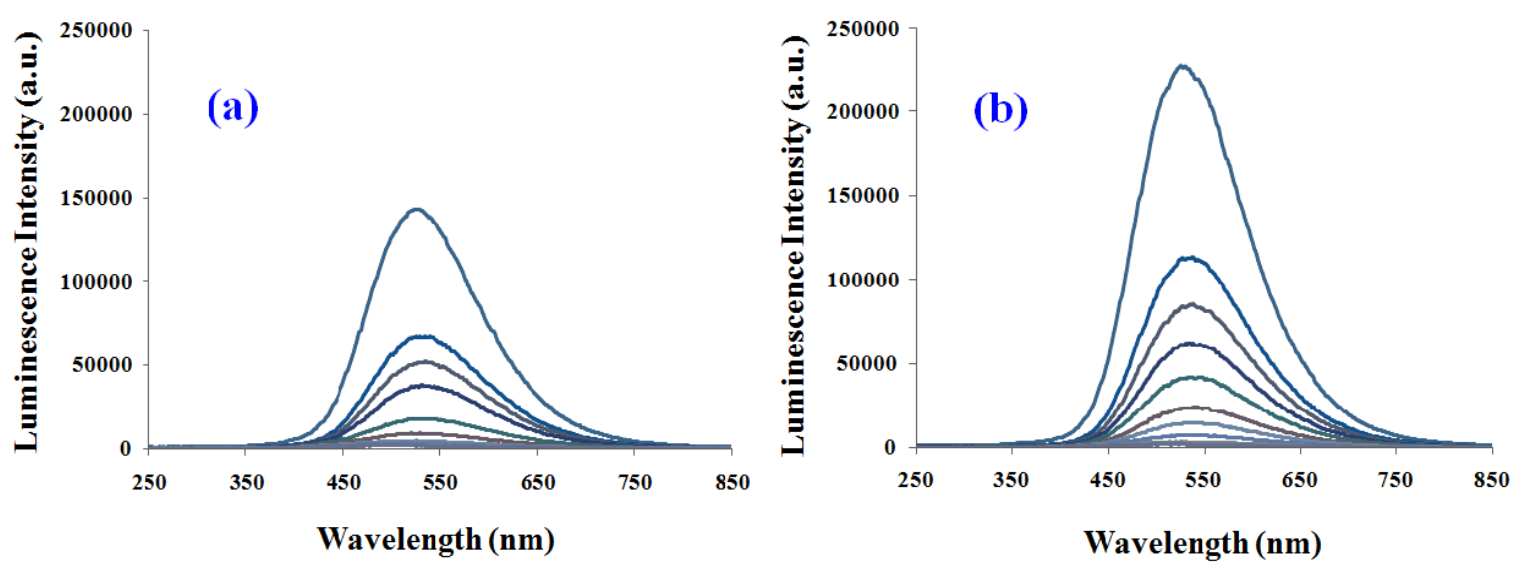

Fig. 10 Laser induced luminescence spectra, obtained at $77 \mathrm{~K}$, of Fabric/TiO $-120{ }^{\circ} \mathrm{C}$ samples (a) before sonication and (b) after sonication. The excitation wavelength was $337 \mathrm{~nm}$ and the step was $1 \mu \mathrm{s}$ in both cases. The used gate width was $10 \mathrm{~ms}$ 


\section{Conclusion}

Woven cotton textile samples loaded with $\mathrm{TiO}_{2}$ NPs were hydrothermally treated at 369 temperatures ranging from $50{ }^{\circ} \mathrm{C}$ to $140{ }^{\circ} \mathrm{C}$. The presence of $\mathrm{TiO}_{2}$ on the samples was verified 370 by several characterization techniques and the photocatalytic activity was found optimized for 371 a hydrothermal treatment at $120{ }^{\circ} \mathrm{C}$, as judged from the results obtained with a model dye 372 Rhodamine 6G (Rh6G). In our quest of photocatalytic pigment fastness, we subjected the samples to ultrasonication to check their ability to remain attached to the surface. In a

374 serendipitous way, we found out that ultrasonication boosted the photocatalytic effect despite 375 a slight partial removal of $\mathrm{TiO}_{2}$ nanoparticles. The study was repeated with Methylene Blue 376 dye, and a similar effect was observed as the photocatalyzed degradation of MB led to a loss 377 of $90 \%$ after $30 \mathrm{~min}$ of ultrasonication of the fabric primarily hydrothermally treated at $378120{ }^{\circ} \mathrm{C}$. Compared to un-sonicated fabric the photocatalyzed degradation using a sonicated 379 catalytic fabric is 4 times better as the non-sonicated fabric degraded MB but left $40 \%$ of the dye.

This work conclusively shows that ultrasonication clearly boosts up the photocatalytic activity of $\mathrm{TiO}_{2}$, and the process could be extended to other types of nanocatalysts such as mixed oxides or noble metal loaded $\mathrm{TiO}_{2}$. The process is simple and could be generalized for pilot testing.

\section{Acknowledgements}

387 The authors would like to thank NATO for financial support through the CATALTEX project 388 No SfP 984842. 


\section{References}

Abid M, Bouattour S, Conceição DS, et al (2016) Hybrid cotton-anatase prepared under mild conditions with high photocatalytic activity under sunlight. RSC Advances 6:58957-58969

Abidi N, Cabrales L, Hequet E (2009) Functionalization of a cotton fabric surface with titania nanosols: applications for self-cleaning and UV-protection properties. ACS applied materials \& interfaces 1:2141-2146

Atashbar MZ, Sun HT, Gong B, et al (1998) XPS study of Nb-doped oxygen sensing TiO2 thin films prepared by sol-gel method. Thin Solid Films 326:238-244. doi: 10.1016/S00406090(98)00534-3

Attia MF, Azib T, Salmi Z, et al (2013) One-step UV-induced modification of cellulose fabrics by polypyrrole/silver nanocomposite films. Journal of Colloid and Interface Science 393:130 137. doi: $10.1016 /$ j.jcis.2012.11.008

Belgacem MN, Czeremuszkin G, Sapieha S, Gandini A (1995) Surface characterization of cellulose fibres by XPS and inverse gas chromatography. Cellulose 2:145-157. doi: 10.1007/BF00813015

Blaser SA, Scheringer M, MacLeod M, Hungerbühler K (2008) Estimation of cumulative aquatic exposure and risk due to silver: contribution of nano-functionalized plastics and textiles. Science of the total environment 390:396-409

Bozzi A, Yuranova T, Guasaquillo I, et al (2005) Self-cleaning of modified cotton textiles by TiO2 at low temperatures under daylight irradiation. Journal of Photochemistry and Photobiology A: Chemistry 174:156-164

Budavari S, O’Neil MJ, Smith A, Heckelman PE (1989) The merck index. Merck Rahway, NJ

Chen C-C, Wang C-C, Yeh J-T (2010) Improvement of odor elimination and anti-bacterial activity of polyester fabrics finished with composite emulsions of nanometer titanium dioxide-silver particles-water-borne polyurethane. Textile Research Journal 80:291-300

Diffey BL (1991) Solar ultraviolet radiation effects on biological systems. Physics in medicine \& biology 36:299

Djaneye-Boundjou G, Bawa LM, Boukari Y, Dovi K (2001) Photodégradation de la rhodamine B et du bleu de méthylène en solution aqueuse. J Soc Ouest-Afr Chim 11:75-94

Errokh A, Ferraria AM, Conceição DS, et al (2016) Controlled growth of Cu2O nanoparticles bound to cotton fibres. Carbohydrate Polymers 141:229-237. doi: 10.1016/j.carbpol.2016.01.019

Fangueiro R (2011) Fibrous and composite materials for civil engineering applications. Elsevier

George S, Kishen A (2007) Photophysical, photochemical, and photobiological characterization of methylene blue formulations for light-activated root canal disinfection. JBO 12:034029. doi: $10.1117 / 1.2745982$

Hadjiivanov KI, Klissurski DG (1996) Surface chemistry of titania (anatase) and titania-supported catalysts. Chemical Society Reviews 25:61-69 
Hamden Z, Boufi S, Conceição DS, et al (2014) Li-N doped and codoped TiO2 thin films deposited by dip-coating: Characterization and photocatalytic activity under halogen lamp. Applied Surface Science 314:910-918. doi: 10.1016/j.apsusc.2014.06.176

Hinsch E, Robinson S (2018) Comparing colorfastness to light of wood-staining fungal pigments and commercial dyes: an alternative light test method for color fastness. Coatings 8:189

Horrocks AR, Anand SC (2000) Handbook of technical textiles. Elsevier

Hristian L, Bordeianu DL, Iurea P, et al (2014) Study of the tensile properties of materials destined to manufacture protective clothing for firemen. Revista de Materiale Plastice 51:405-409

Li G, Li Y, Chen G, et al (2015) Silk-based biomaterials in biomedical textiles and fiber-based implants. Advanced healthcare materials 4:1134-1151

McKinlay AF (1987) A reference action spectrum for ultraviolet erythema in human skin. CIE journal 6:17-22

Meilert KT, Laub D, Kiwi J (2005) Photocatalytic self-cleaning of modified cotton textiles by TiO2 clusters attached by chemical spacers. Journal of molecular catalysis A: chemical 237:101108

Min L, Wu X-Z, Tetsuya S, Inoue H (2007) Time-resolved chemiluminescence study of the TiO2 photocatalytic reaction and its induced active oxygen species. Luminescence: The journal of biological and chemical luminescence 22:105-112

Mohammad F (2015) High-energy radiation induced sustainable coloration and functional finishing of textile materials. Industrial \& Engineering Chemistry Research 54:3727-3745

Monzavi A, Montazer M, Malek RMA (2017) A Novel Polyester Fabric Treated with Nanoclay/Nano TiO2/PAMAM for Discoloration of Reactive Red 4 from Aqueous Solution Under UVA Irradiation. J Polym Environ 25:1321-1334. doi: 10.1007/s10924-016-0905-1

Ochiai T, Fujishima A (2012) Photoelectrochemical properties of TiO2 photocatalyst and its applications for environmental purification. Journal of Photochemistry and photobiology C: Photochemistry reviews 13:247-262

Popov AP, Priezzhev AV, Lademann J, Myllylä R (2005) TiO2 nanoparticles as an effective UV-B radiation skin-protective compound in sunscreens. Journal of Physics D: Applied Physics $38: 2564$

Program NT (1989) NTP Toxicology and Carcinogenesis Studies of Rhodamine 6G (CI Basic Red 1)(CAS No. 989-38-8) in F344/N Rats and B6C3F1 Mice (Feed Studies). National Toxicology Program technical report series 364:1

Rehman F, Adeel S, Hanif R, et al (2017) Modulation of marigold based lutein dye and its dyeing behaviour using UV radiation. Journal of Natural Fibers 14:63-70

Salvador P (2007) On the nature of photogenerated radical species active in the oxidative degradation of dissolved pollutants with $\mathrm{TiO} 2$ aqueous suspensions: a revision in the light of the electronic structure of adsorbed water. The Journal of Physical Chemistry C 111:17038-17043

Scott RA (2005) Textiles for protection. Elsevier 
Tariq MA, Faisal M, Saquib M, Muneer M (2008) Heterogeneous photocatalytic degradation of an anthraquinone and a triphenylmethane dye derivative in aqueous suspensions of semiconductor. Dyes and Pigments 76:358-365

Vieira Ferreira LF, Ferreira Machado IL (2007) Surface Photochemistry: Organic Molecules within Nanocavities of Calixarenes. https://www.ingentaconnect.com/content/ben/cddt/2007/00000004/00000004/art00003.

472 Wilusz E (2008) Military textiles. Elsevier

Xue C-H, Jia S-T, Chen H-Z, Wang M (2008) Superhydrophobic cotton fabrics prepared by sol-gel coating of TiO2and surface hydrophobization. Sci Technol Adv Mater 9:035001. doi: $10.1088 / 1468-6996 / 9 / 3 / 035001$

Yuranova T, Mosteo R, Bandara J, et al (2006) Self-cleaning cotton textiles surfaces modified by photoactive $\mathrm{SiO} 2 / \mathrm{TiO} 2$ coating. Journal of Molecular Catalysis A: Chemical 244:160-167

Zou F, Zhou J, Zhang J, et al (2018) Functionalization of Silk with In-Situ Synthesized Platinum Nanoparticles. Materials 11:1929. doi: 10.3390/ma11101929 